\title{
Calculation of foundation settlement on a overconsolidated base
}

\author{
Armen Ter-Martirosyan ${ }^{1, *}$, and Ivan Luzin ${ }^{1}$ \\ ${ }^{1}$ Moscow State University of Civil Engineering, Yaroslavskoe shosse, 26, Moscow, 129337, Russia
}

\begin{abstract}
The article presents experimental and theoretical bases of overconsolidated soils deformation. The effect of preliminary soil compaction on its deformation under conditions of compression is shown. Based on this dependence, a method is proposed for calculating the foundation settlement on a overconsolidated base, taking into account the pre overburden pressure. The obtained method is compared with the results of the problem solution by the finite element method.
\end{abstract}

\section{Introduction}

Overconsolidated soils often lie at the base of the foundations of buildings and structures on the territory of the Russian Federation and the Europe countries. Overconsolidated soils are those soils that experienced a greater load in the history of their formation than the natural weight of the soils lying above [1]. Most often, such a load is due to the pressure of ice during the glacial periods.

The results of experimental research clay soils show that under repeated loading compression curve on a semilogarithmic scale is not linear and has a clear inflection point at a pressure equal to pre overburden pressure [2]. Based on the results of experimental researches, it is possible to propose a method for determining the settlement of foundations on overconsolidated bases.

\section{Experimental researhes}

To study the deformation of overconsolidated soils, experimental studies were carried out in REC Geotechnika MSUCE. To produce a complex for the preparation and testing of samples with a given pressure of re-consolidation, twin samples of clay loam with a density $\rho=2.05 \mathrm{~g} / \mathrm{cm} 3$ and a moisture content of $\mathrm{W}=12 \%$ were created. Further, a step load of up to $400 \mathrm{kPa}$ was applied to the samples, followed by keeping for at least 4 weeks. This procedure is associated with the need to create new water-colloidal bonds in soil samples $[3,4]$.

\footnotetext{
* Corresponding author: gic-mgsu@mail.ru
} 
After stepwise unloading of the samples, standard compression tests were carried out. Figure 1 shows the results of preparation and testing-the averaged compression curve.

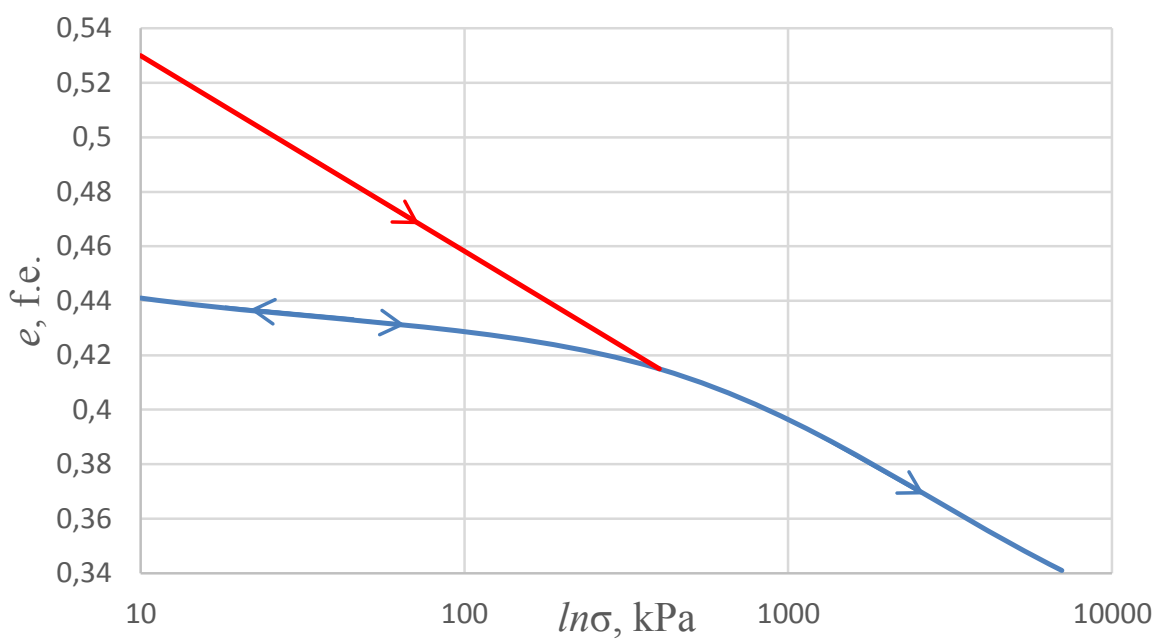

Fig. 1. The experimental compression curve obtained in the load cycle (red line), unloading and reloading (blue line)

Analysis of figure 1 showed that at pressures lower than the pre overburden pressure $\left(\sigma_{z}<\sigma_{p}\right)$, only resilient deformations occur in the reconsolidated soil. When the pre overburden pressure is exceeded $\left(\sigma_{z} \geq \sigma_{p}\right)$, the compression curve at a semilogarithmic scale sharply changes the angle of inclination to the horizontal, which is due to plastic deformations in the soil $[5,6]$. This effect can be applied to the calculation of the fondation settlement on the overconsolidated bases, on the basis of the method of layerwise summation, which is the main method for calculating the precipitate in SP 22.13330.2016.

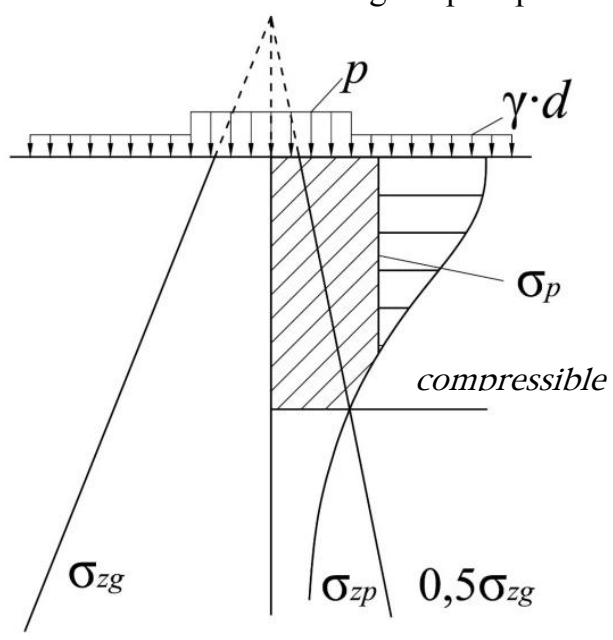

Fig. 2. Calculation scheme of the method of layerwise summation taking into account the pre overburden pressure

The finite width foundation settlement by the method of layerwise summation is defined as: 


$$
S=\beta \sum_{i=1}^{n} \frac{\sigma_{z p, i} \cdot h_{i}}{E_{i}}
$$

here is $\beta$ - a dimensionless coefficient equal to $0.8 ; \sigma_{z p, i}$ - the average value of the vertical normal stress from the external load in the $i$-th layer of the soil along the vertical, passing through the center of the basement; $h_{i}$ - thickness of the $i$-th layer; $E_{i}$ is the deformation modulus of the $i$-th layer.

Based on the results of the experiments (Fig. 1) and selecting on the design diagram the method of layer-by-layer summation of the pre overburden pressure diagram (Fig. 2), the settlement of the base folded by overconsolidated soils can be determined in the first approximation by the formula $[7,8]$ :

$$
\begin{gathered}
S=\beta \sum_{i=1}^{n} \frac{\left(\sigma_{z p, i}-\sigma_{p}\right) \cdot h_{i}}{E_{i}}+\beta \sum_{i=1}^{n} \frac{\sigma_{p} \cdot h_{i}}{E_{e, i}} \text { when } \sigma_{z p, i}>\sigma_{p} \\
S=\beta \sum_{i=1}^{n} \frac{\sigma_{z p, i} \cdot h_{i}}{E_{e, i}} \text { when } \sigma_{z p, i} \leq \sigma_{p}
\end{gathered}
$$

where $\sigma_{p}$ is the value of the pre overburden pressure; $E_{e, i}$ - deformation modulus of soil in the cycle of unloading and re-loading.

Let us give an example of calculation.

Let the base, folded by a clay overconsolidated soil, be deformed under the action of a distributed load by the value $p=400 \mathrm{kPa}$ over a strip of width $b=10 \mathrm{~m}$. Parameters of clay soil: $\gamma=20 \mathrm{kN} / \mathrm{m}^{3} ; E_{i}=20 \mathrm{mPa} ; E_{e, i}=100 \mathrm{mPa}$. It is necessary to find the base settlement at different values of the pre overburden pressure: $0,200 \mathrm{kPa}$ and $400 \mathrm{kPa}$. Define the lower boundary of the compressible boundary (Figure 3).

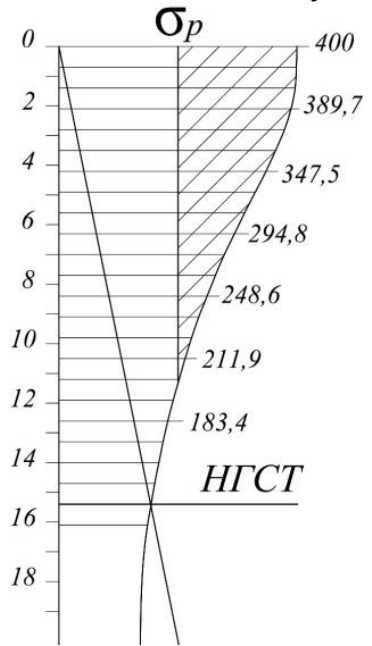

Fig. 3. Calculation scheme for determining the compressible boundary and the settlement by the method of layerwise summation under given conditions

According to the results of calculations, the thickness of the compressible boundary at the given parameters is $15.4 \mathrm{~m}$. We also note in the figure the diagram of the pre overburden pressure diagram. The region to the right of the diagram can be marked by 
shading. The base sediment in the shaded area will be determined at the value of the strain modulus $E_{i}=20 \mathrm{mPa}$, and the region to the left of the diagram is at $E_{i}=100 \mathrm{mPa}$.

Consequently, we can determine the base settlement at different values of the pre overburden pressure.

The results of solving the problem are given in Table 1 .

Table 1. The foundation settlement at different values of $\sigma_{p}$

\begin{tabular}{|l|l|l|l|}
\hline$\sigma_{p}, \mathrm{kPa}$ & 0 & 200 & 400 \\
\hline Settlement, mm & 181 & 78 & 45 \\
\hline
\end{tabular}

Analysis of the results of solving the problem of settlement the base, folded by a overconsolidated clay soil, showed that taking into account the pre overburden pressure in the settlement calculation by the method of layerwise summation can reduce the calculated settlement by up to 4 times [9].

This problem can also be solved by the numerical method (FEM) in Plaxis 2D. The conditions of the problem were set similar to the previous problem, i.e. a similarly compressible boundary and parameters of the soils were specified. To take into account the residual stresses and deformations in the ground, the hardening soil model was chosen as the calculation one [10-12]. This model most correctly takes into account the soil behavior during unloading, repeated loading and preloading, which is the best suited for the solution of the task. However, this model requires the correct input of input parameters, including strain modules under compression loading $\left(E_{\text {oed }}\right)$, at 50\% loading $\left(E_{50}\right)$ and at unloading ( $\left.E_{u r}\right)$. When solving this problem, these parameters were set as follows: $E_{\text {oed }}=16 \mathrm{mPa}$; $E_{50}=20 \mathrm{mPa}$ and $E_{u r}=100 \mathrm{mPa}$. This problem was also solved for three different values of the pre overdurden pressure. To do this, the soil massive was subjected to preliminary compaction in a compression mode with a given value of the pre overburden pressure, after which a complete unloading was performed. After preliminary compaction and unloading, a uniformly distributed load $\mathrm{p}=400 \mathrm{kPa}$ over a strip of width $\mathrm{b}=10 \mathrm{~m}$ was applied on the surface of the soil massive. The results of the solution of the problem are shown in Figures 4 and 5 .

By the results of the solution of the problem by a numerical method, it can also be concluded that taking into account the pre overburden pressure in the settlement calculating can reduce their calculated values up to 4 times. In Table 2 we give a comparison of the values of the calculated sediments by the method of layerwise summation (MLS) and by the finite element method (FEM).

Table 2. Comparison of settlement calculated according to the proposed method (PM) and using the finite element method (FEM)

\begin{tabular}{|l|l|l|l|l|}
\hline \multicolumn{2}{|l|}{$\sigma_{p}, \mathrm{kPa}$} & 0 & 200 & 400 \\
\hline \multirow{2}{*}{ Settlement, mm } & PM & 181 & 78 & 45 \\
\cline { 2 - 6 } & FEM & 197 & 85 & 55 \\
\hline
\end{tabular}

It can be seen that the results of the calculations have good convergence. Therefore, the proposed method can be used to the settlement calculate of the bases folded by overconsolidated soils. 


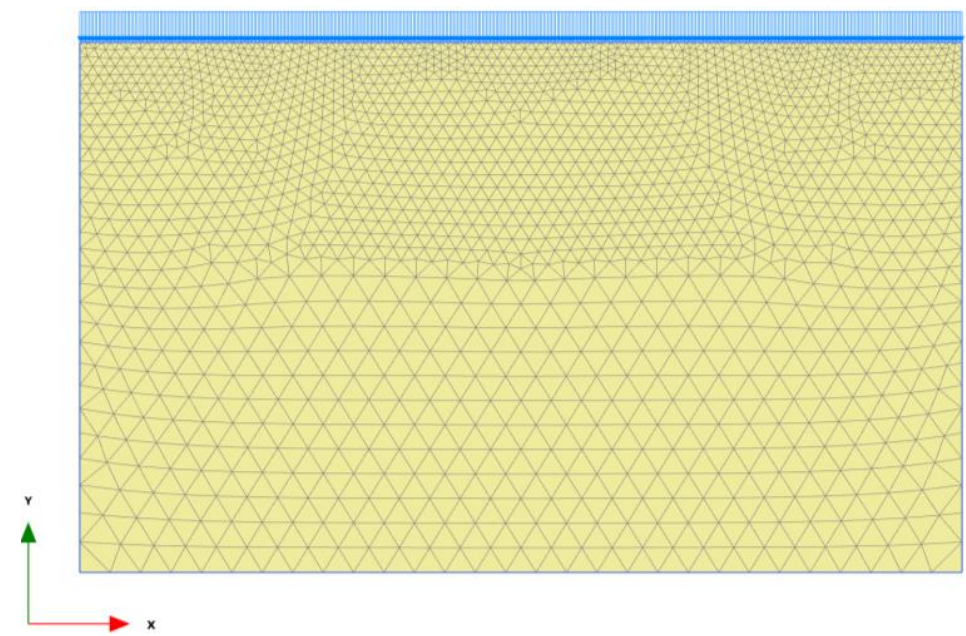

Fig. 4. Calculation scheme of the task at the phase of consolidation of the clay soil massive under the action of a uniformly distributed load in the compression mode

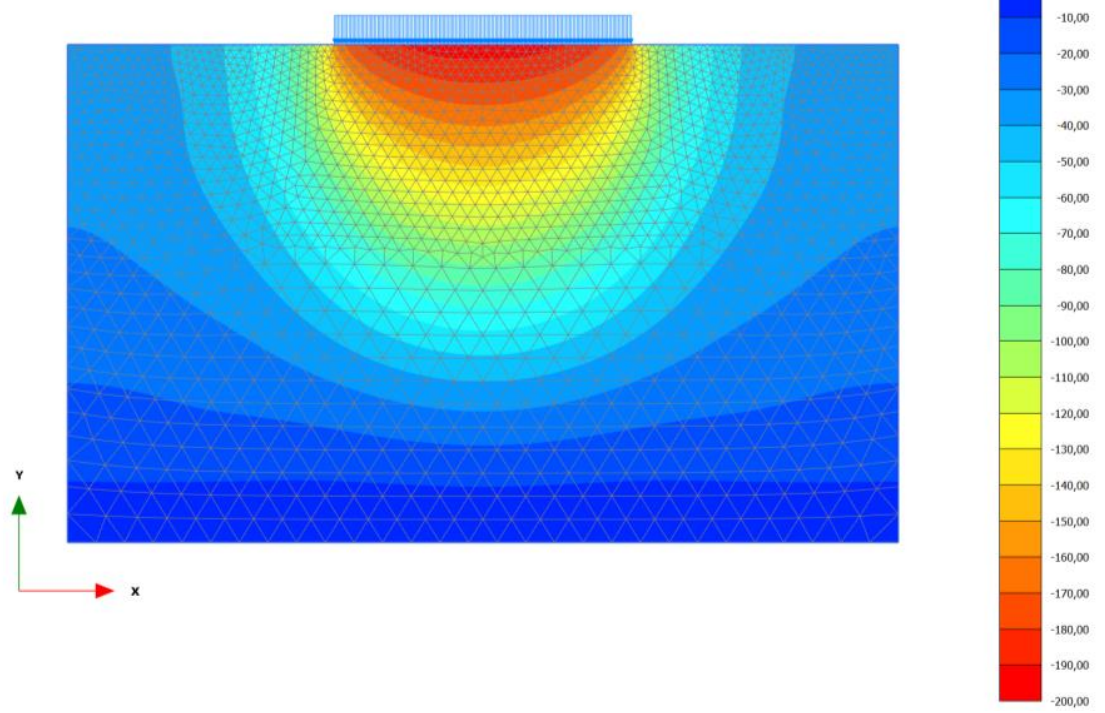

Fig. 5. Colour shadings of the calculation at the phase of consolidation of the clay soil massive under the action of a uniformly distributed load in the compression mode

\section{Conclusion}

Main conclusions:

1. The solution of the problem for the base under the action of loading by a numerical method in an elastic-plastic setting showed that residual stresses and deformations in clay soil are formed both under compression action and under the action of local distributed load of finite width.

2. The solution of the one-dimensional compaction problem in an elastoplastic formulation with nonlinear properties of volume change and deformation has shown that the formation of residual stresses and deformations in a clay soil is due to its elastic-plastic properties. 
3. A method for determining the foundation settlement on a overconsolidated clay soil is proposed and based on the method of layer-by-layer summation, which is the main method for determining the precipitation in SP 22.13330.2016.

4. The results of calculating the settlement according to the proposed method have good convergence with the results of solving a similar problem by a numerical method in an elastic-plastic formulation.

This work was financially supported by Ministry of Education and Science of the Russian Federation (\#NSh-3492.2018.8). All tests were carried out using research equipment of The Head Regional Shared Research Facilities of the Moscow State University of Civil Engineering (RFMEFI59317X0006)

\section{References}

1. V.T. Trofimov, Soil science, 1024 (Moscow, Moscow State University, 2005)

2. Gu Chaun, Wang Jun, Cai Yuanqiang, Sun Lei, Wang Peng, Dong QuanYang, Soil and Foundations, 56, 3, 427-439 (2016)

3. S. Jocković, M. Vukićević, Computers and Geotechnics, 83, 16-29 (2017)

4. G.G. Boldyrev, D.V. Arefiev, A.V. Gordeyev, Inzhenernye izyskaniya, 8, 16-23 (2010)

5. A.N. Trufanov, O.A. Shulyatyev, A.V. Rostovtsev, G.U. Gadsalyamov, Inzhenernye izyskaniya, 11, 32-39 (2014)

6. A. Casagrande, Proc. of the 1-st International Soil Mechanics and Foundation Engineering Conference, 3, 60-64 (1936)

7. D.E. Becker, J.H.A. Crooks, K. Been, M.G. Jefferies, Canadian Geotechnical Journal, 24, 549-564 (1987)

8. Z.G. Ter-Martirosyan, Soil mechanics, 550 (Moscow, ASV, 2009)

9. L.N. Kachanov, Basics of the plasticity theory, 420 (Moscow, Nauka, 1969)

10. Nadai A. Plasticity and destruction of solid bodies. Moscow, Nauka (1969) 863 p.

11. S. P. Timoshenko, Theory of elasticity, 560 (Moscow, Nauka, 1975)

12. S.S. Vyalov, Rheological basis of soil mechanics, 447 (Moscow, Vyshaya shkola, 1978)

13. R.F. Ganiev, S.R. Ganiev, V.P. Kasilov, A.P. Pustovgar, Wave Technology in Mechanical Engineering: Industrial Applications of Wave and Oscillation Phenomena, (Wiley, 2015)

14. K.S. Fahmi, M.Y. Fattah, A. Pustovgar, MATEC Web of Conferences, 170, 03001 (2018) 